\title{
Application of ultrasonography in female infertility: a comprehensive review
}

\author{
Tochukwu C. Okeke ${ }^{1 *}$, Kennedy K. Agwuna ${ }^{2}$, Cyril C. Ezenyeaku ${ }^{3}$, Lawrence C. Ikeako
}

\author{
${ }^{1}$ Department of Obstetrics \& Gynecology, University of Nigeria Teaching Hospital, Enugu, Nigeria \\ ${ }^{2}$ Department of Radiology, University of Nigeria Teaching Hospital, Enugu, Nigeria \\ ${ }^{3}$ Department of Obstetrics \& Gynecology, Anambra State University Teaching Hospital, Amaku, Awka, Nigeria
}

Received: 24 August 2015

Accepted: 09 September 2015

*Correspondence:

Dr. Tochukwu C. Okeke,

E-mail: tcokeke2014@yahoo.com

Copyright: (C) the author(s), publisher and licensee Medip Academy. This is an open-access article distributed under the terms of the Creative Commons Attribution Non-Commercial License, which permits unrestricted non-commercial use, distribution, and reproduction in any medium, provided the original work is properly cited.

\begin{abstract}
The quest for detailed evaluation of the uterus, fallopian tubes, and ovaries that is radiation free, inexpensive, readily available, non-invasive, relatively less time consuming and easily repeatable in female infertility has resulted in further studies. However, ultrasonography (US) remains the first line indispensable tool for gynecologic workup, monitoring and treating infertility. The aim is to review the current knowledge regarding the application of ultrasonography in female infertility. This was a descriptive review of ultrasonography in female infertility. We searched several databases (Medline, Google scholar, PubMed) with keywords "ultrasonography and female infertility", "evaluation of female infertility", "role of ultrasonography in female infertility:, and imaging in female infertility". Female infertility is multifactorial in origin. Ultrasonography is the most widely used imaging in gynecology and has revolutionized the management of female infertility worldwide. The recognition, evaluation and treatment of female infertility are complicated, complex, stressful and emotionally devastating for most couples. The couple's emotional state should be supportive, informative and well tolerated. Female infertility is an immense stress to couples, families and relatives worldwide. The causes are multifactorial in origin with both congenital and acquired problems of the uterus, fallopian tubes and ovaries. Ultrasound plays an important role in female infertility workup with hysterosalpingography (HSG), sonohysterography (Sono-HSG) and magnetic resonance imaging (MRI), each playing a complimentary role in the screening, diagnosis and/or management of female infertility.
\end{abstract}

Keywords: Female Infertility, Ultrasonography, HSG, Sono-HSG, MRI

\section{INTRODUCTION}

Infertility is a cause of immense stress to couples, families and relatives especially in sub-Saharan Africa where marriage is revered, respected and tied to child bearing. ${ }^{1-3}$ The emotional, physiological, psychological, sexual, social, and financial burden of infertility on the family, are enormous. ${ }^{3-6}$

Infertility is the inability of a couple to achieve pregnancy after one year of regular, unprotected intercourse. Infertility is relative. In both men and women the fertility process is complex. Infertility affects about
$10-15 \%$ of all couples. ${ }^{5}$ Males and females are equally affected. ${ }^{5}$ The physician must view the couple as a unit. The initial evaluation is often perceived as a stressful experience. The couple is seen together. This approach is helpful and saves time. Female infertility workup is incomplete without the application of ultrasonography (US). However, it is important to note that infertility in females is multifactorial in origin. ${ }^{5}$

US is a useful and first line investigation tool available to gynecologists to assess the causes of female infertility and to institute some of the treatments used to ameliorate infertility. US is an effective, safe, inexpensive, radiation 
free, non-invasive tool, readily available, easy to use and easily repeatable approach to evaluate female infertility worldwide. ${ }^{6}$ It improves the quality of care provided in female infertility workup by facilitating rapid diagnosis and the visualization of changes in female reproductive physiology required to direct therapy.

US is the most widely used method of imaging in gynecology and has revolutionized the management of female infertility worldwide. ${ }^{7}$

Ultrasonographic limitations include limited field of view, subjective errors, interference by obesity or by gaseous bowel loops, suboptimal visualization of fallopian tubes and broad ligament, failure to delineate small ovaries, and inability to obtain images in the surgical plane. 5

The recognition, evaluation and treatment of female infertility are complex and stressful for most couples. However, the clinician should not ignore the couple's emotional state. Information should be supportive, informative and well tolerated.

The aim of this review is to provide clinicians with the role of ultrasonography in the evaluation of female infertility and management of women who want to achieve pregnancy.

\section{METHODOLOGY}

This was a 6-month descriptive review of the application of US in female infertility. Relevant literature search on this topic was from January $1^{\text {st }}$ to June $30^{\text {th }} 2015$. A search of literature on application of US in female infertility published in English was conducted. Relevant materials were selected. We searched several databases on application of US in female infertility from inception to January $1^{\text {st }} 2015$ with keywords "ultrasonography and female infertility", female infertility workup, female infertility investigations, imaging in female infertility and evaluation of female infertility and role of ultrasound in female infertility. We also searched references in retrieved articles, book chapters, review articles, conference papers, technical reports, abstracts and internet articles using Medline, Google scholar and PubMed database. These materials were critically reviewed and the inclusion of individual articles was based on scientific merit and clinical relevance.

\section{Historical perspective}

Ultrasound was first used in obstetrics and gynecology by Ian Donald and his colleagues in Scotland in 1958. Ian Donald was Regius Professor of Midwifery at the University of Glasgow. ${ }^{9}$ Ultrasound has undergone several developments since introduction. Both transabdominal ultrasound (TAS) and transvaginal ultrasound (TVS) are used in gynecology. Transabdominal approach gives a more panoramic view of the pelvis, but transvaginal ultrasound offers several advantages in gynaecology. ${ }^{10}$

The ultrasound of the female pelvis and the morphologic changes in the uterus and ovaries in relation to the menstrual cycle was described by Kratochwil et al in 1972. ${ }^{11}$ Later in 1977 Hackerloer et al described the ultrasonic measurement of follicular size after gonadotropin stimulation by means of the transabdominal technique with full bladder. ${ }^{12}$ Hackerloer with other coworkers demonstrated the linear relation between follicular growth and serum concentration of oestradiol in the spontaneous menstrual cycle. ${ }^{13}$ This finding was confirmed by Kerin et al for timing of oocyte retrieval in natural cycle in invitro fertilization (IVF). ${ }^{14}$ These observations were made by means of static ultrasound scanning. O'Herlithy et al demonstrated that real-time sector scanning yielded similar results. ${ }^{15}$ This technique gradually replaced static scanning in monitoring the spontaneous or induced cycle. The validity of transabdominal measurements of follicular size and number was confirmed with laparoscopic findings. ${ }^{16}$ Seibel et al established the role of ultrasound in ovulation induction. $^{17}$ The most important advancement in infertility care was the introduction of transvaginal ultrasonography (TVS). This was reported by Gleicher et al in 1983 after successful imaging of ovaries by transvaginal sector probe and oocyte retrieval for invitroembryo transfer (IVT-ET) - through culdocentesis. In 1984 Dellenbach et al described transvaginal ultrasonically guided oocyte retrieval by means of follicular puncture. ${ }^{18}$ Later Schwimer and Lebovic in the mid-1980s introduced the technical improvements that provided TVS with its powerful diagnostic and therapeutic properties. ${ }^{19,20}$ They used $3.5 \mathrm{MHz}$ transabdominal transducers via the transvaginal route. This technique did not gain wide acceptance because it did not result in substantial improvement in image resolution. It was later that TVS gained popularity after technical advances in instrumentation and imaging. Images of better axial and lateral resolution and enhanced quality were developed as a result of proximity of the vaginal probe to pelvic structures, avoidance of attenuation caused by intestinal gas or abdominal wall muscle and fat with development and incorporation of probes with higher frequencies. The use of high frequency ( 5 to $7.5 \mathrm{MHz}$ ), high resolution transvaginal probes and improvements in magnification imaging and signal processing provided the opportunity for investigating of the female reproductive system.

Recently, TVS has developed and expanded as one of the most powerful tools for the investigation and management of female infertility. It is well accepted by patients and sonographers because it eludes the discomfort inherent in the need for a full and distended bladder. TVS also provides the clinician the ability to visualize the pelvic organs within a millimeter range. This ability helps in the definitive diagnosis of pelvic abnormalities with even greater accuracy than the routine 
bimanual pelvic examination. ${ }^{21}$ Comparative studies have proved the superiority of TVS over TAS in monitoring ovulation induction. ${ }^{22,23}$

Further improvements in technology and instrumentation have made TVS feasible as an office procedure. ${ }^{24} \mathrm{~A}$ recent incorporation in the investigation of female infertility is the use of Doppler Velocimetry of the pelvic organs. This has increased our understanding of reproductive physiology and pathology.

\section{Anatomy of female genital organs}

The internal organs of reproductive system include: the vagina, the uterus, the fallopian tubes and the ovaries.

The vagina is a distensible fibromuscular tube extending from the vulva to the uterine cervix. It is about $9 \mathrm{~cm}$ long with its upper half above the pelvic floor and lower half within the perineum. ${ }^{6,7}$ The recess between the cervix and the vagina is called the fornix. Anterior to the vagina, sit the urinary bladder and urethra; posterior to it is the rectum and anal canal. Laterally, it is bounded by the levator ani and pelvic fascia.

The uterus is a hollow, pear-shaped organ with a thickwalled fibromuscular structure that measures about $8 \mathrm{~cm} \mathrm{x}$ $5 \mathrm{~cm} \times 2.5 \mathrm{~cm}$ in a nulliparous young adult. ${ }^{7}$ However, the size and shape of the uterus depend on the woman's age and parity. The uterus is divided into the body and the cervix. The uterine body is further divided into 3 parts namely the fundus, the main body and the isthmus. Uterus serves as an incubation chamber and allows for implantation of a fertilized ovum and accommodates the fetus during pregnancy. ${ }^{25}$ The cervix serves as the connection between the uterine body and the vagina. The opening or the os of the cervical canal is circular in nulliparous women and slit-like in the parous. ${ }^{6}$

The fallopian tube is about $10-12 \mathrm{~cm}$ in length and lies in the upper border of the broad ligament bilaterally. It runs from uterine cornu to the ovary. Each fallopian tube is divided into 4 parts: funnel shaped infundibulum and its fimbriae, wide ampulla, narrow isthmus, and the intramural part that pierces the uterine wall. The fallopian tubes, ovaries and associated connective tissue (parametria) are collectively called the adnexae. Fallopian tubes provide the path for the ovum to travel from the ovary to the uterus.

Also it is the location of fertilization in its lateral one third (the ampullary portion of the tube). ${ }^{6,7}$

The ovaries are almond-sized organ. They are located in the lateral pelvic wall adjacent to the bifurcation of the common iliac vessels, posterior to the broad ligament and anterior to the ureter. It measures $4 \mathrm{~cm} \mathrm{x} 2 \mathrm{~cm} \mathrm{x} 1 \mathrm{~cm}$ and is attached to the broad ligament by the mesovarium. Ovarian size and location are dependent on age, menstrual status and parity. The ovarian parenchyma is divided into two parts: the medulla, where the blood supply enters and exits the ovary and the cortex, which contains multiple follicles in varying stages of development. Before puberty, the ovaries are smooth, but they get progressively scared with age. Postmenopausal ovaries are shrunken and have a surface pitted with scars. The ovaries are the ovum-producing organs and they also produce female sex steroids. $^{25}$

\section{Causes of female infertility}

Pelvic causes of female infertility are varied and range from ovarian to tubal and peritubal abnormalities, uterine and cervical disorders. $^{26,27}$

\begin{tabular}{|c|c|c|}
\hline 1. & & Ovarian Factors \\
\hline & $\checkmark$ & Polycystic ovarian syndrome (PCOS) \\
\hline & $\checkmark$ & Hypothalamic amenorrhea \\
\hline & $\checkmark$ & Luteinized unruptured follicle \\
\hline & $\checkmark$ & Ovarian infections or tumors \\
\hline 2 . & & Tubal factors \\
\hline & $\checkmark$ & Ectopic pregnancy \\
\hline & $\checkmark$ & Endometriosis \\
\hline & $\checkmark$ & Pelvic inflammatory disease (PID) \\
\hline & & Uterine factors \\
\hline & $\checkmark$ & Developmental anomalies \\
\hline & $\checkmark$ & Adhesions (Asherman's syndrome) \\
\hline & $\checkmark$ & Infections \\
\hline & $\checkmark$ & Tumors \\
\hline I. & & Cervical Factors \\
\hline & $\checkmark$ & Cervicitis \\
\hline & $\checkmark$ & Abnormal cervical mucus \\
\hline 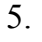 & & Endocrine factors \\
\hline & $\checkmark$ & Kallman's syndrome \\
\hline & $\checkmark$ & Fertile eunuchism \\
\hline & $\checkmark$ & Panhypopituitarism \\
\hline & $\checkmark$ & Hypothyroidism \\
\hline & $\checkmark$ & Adrenal insufficiency \\
\hline 6. & & Miscellaneous causes \\
\hline & $\checkmark$ & Drugs \\
\hline & $\checkmark$ & Radiation \\
\hline & $\checkmark$ & Coital difficulties \\
\hline & & Idiopathic \\
\hline
\end{tabular}

\section{Work up of female infertility}

After a detailed history, a careful interview and a thorough physical examination should include both physiological and anatomical assessment. ${ }^{27}$ The physiological assessment should target the hormonal axis from the hypothalamo-pituitary axis to the uterus and ovaries, and also the thyroid and adrenal glands. The purpose is to establish whether the endocrine glands function properly and whether the pelvic and reproductive organs respond appropriately to the hormonal cyclical stimulation. The anatomical assessment is to define the morphology of the pelvic organs, since developmental anomalies or acquired defects may interfere with normal reproduction. 


\section{Ovulatory function tests}

1. Basal body temperature recordings

2. Endometrial biopsy to document secretory changes in the endometrium

3. Measurement of a mid-luteal serum progesterone

4. An over-the-counter urinary ovulation prediction kit. These do not involve pelvic sonography.

5. Daily ultrasounds to follow the development and ultimately the disappearance of a follicle (the most accurate method of documenting ovulation). ${ }^{28}$

\section{Tubal patency tests}

1. Hystero-salpingogram (HSG): First line test for evaluation of tubal patency because of its therapeutic and diagnostic benefits. $^{29}$

2. Tubal insufflation with $\mathrm{CO}_{2}$ (Rubins Test)

3. Laparoscopy with chromotubation

4. Fluoroscopic/hysteroscopic selective tubal cannulation

5. Sono-HSG

\section{Postcoital examination (Sims-Huhner test)}

This is used to evaluate the cervical factors and to establish that intercourse is normal. ${ }^{27}$

\section{Pelvic sonography}

This is the most valuable, an efficient and inexpensive scoring tool to detect developmental or acquired uterine and ovarian pathology. Female infertility that is due to gynecologic abnormalities and/or ovulation disorders requires ultrasound as valuable contributor in its work up. $^{27}$

\section{Role of ultrasonography in female infertility}

US offer the following contributions in the investigation and treatment of female infertility.

\section{To assess the anatomy of the pelvic organs}

Developmental anomalies or abnormal mass or fluid collection can be detected by either transabdominal sonography (TAS) or Transvaginal Sonography (TVS).

\section{To monitor the development and evolution of ovarian follicles}

US is an efficient cost effective modality for studying the female reproductive organs and monitoring the functional changes during spontaneous and induced cycles. ${ }^{30}$ During ovulation induction with clomiphene citrate or human menopausal gonadotropin (hMG), TVS is used to monitor the development of ovarian follicles. This is carried out from day 7 of the patient's cycle, preferably on a daily basis. This allows the clinician to manipulate and adjust the dosage of medication. During the administration of medication, follicular monitoring with serial TVS and determination of serum and urine estradiol levels should be performed. A follicle is considered mature when it measures $15-18 \mathrm{~mm}$ in mean diameter. Ovulation is thought to occur when fine echoes are seen in the mature follicle and this is associated with serum estradiol value of about $400 \mathrm{pg} / \mathrm{ml}$ or urine oestrogen excretion levels of $80-150 \mu \mathrm{g} /$ day. $^{27}$

\section{To evaluate the endometrium}

Changes in the endometrial thickness and variation in uterine blood flow may be determined with US during the menstrual cycle and during ovulation induction. Ultrasound allows the study of the 3 main implantation markers: endometrial thickness, endometrial volume and endometrial morphological patterns. ${ }^{31,32}$ For measurement of blood flow, the role of color Doppler is required ${ }^{33}$. Some authors are of the opinion that when the Pulsatility Index (PI) of the endometrium is over 3.0, implantation is unlikely. The relationship between the sonographic appearance of the endometrium and the success or failure of pregnancy is still under investigation. ${ }^{33-35}$

To guide oocyte retrieval (follicular aspiration) and in vitro fertilization-embryo transfer (IVF-ET) or intrafallopian transfer fertilization

Once a mature follicle is detected, the oocyte may be retrieved using one of the following techniques: Laparoscopic aspiration, or transvesical or transvaginal aspiration under ultrasound guidance. Fertilization may be performed in vitro or in the uterus (intrauterine insemination) or in the fallopian tube (intrafallopian transfer) under ultrasound-guided cannulation. The embryo transfer (ET) procedure is the final important step in IVF process. This is a critically important procedure irrespective of how good the IVF laboratory culture environment is, the clinician can ruin the whole procedure with a carelessly performed embryo transfer. The entire IVF cycle depends on delicate placement of the embryo at the proper location of the endometrial cavity with minimal trauma and manipulation under ultrasound guided ET. ${ }^{36,37}$ Ultrasound guided embryo transfer has a number of potential benefits such as: The catheter could be bent to easily pass through the cervical canal and follow the uterine axis, which helps to prevent stimulation and reduction in incidence of difficult transfers, endometrial trauma and bleeding that can cause excessive fundo-uterine contractions at the time of embryo transfer has been associated with lower clinical pregnancy rates. ${ }^{38-41}$ Secondly, the entire process of catheterization and release of the embryos can be visualized, making it easier to place the embryo in the correct position within the uterus and decrease the chance of improper embryo placement..$^{38,42,43}$ The main disadvantage of using ultrasound guidance during embryo transfer is the additional time and personnel required with patient discomfort due to a full bladder and the urge to urinate. ${ }^{35}$ 


\section{To avoid the development of ovarian hyperstimulation syndrome (OHSS)}

The syndrome usually occurs 5 to 8 days following administration of hMG. It consists of pain, electrolyte imbalance associated with ascites and pleural effusions, extremely high level of serum estradiol $(>3000 \mathrm{pg} / \mathrm{ml})$ and massive stromal edema of the ovaries. Patients with large follicles $(>15 \mathrm{~mm})$ in the ovaries are unlikely to develop hyperstimulation, which tends to occur in ovaries with multiple small follicles or in women who have just conceived following induction. Medication should be stopped if urine oestrogen excretion levels reach $150 \mu \mathrm{g} /$ day. It is important to point out that severe OHSS is rare, occurring in less than $1 \%$ of patients. ${ }^{44}$ The grossly enlarged ovaries $(>10 \mathrm{~cm})$ contain multiple echopoor lesions that represent either atretic follicles or areas of hemorrhage in the glands. The ovaries are prone to torsion, which may be detected by color Doppler sonography. Other possible complications are spontaneous rupture, thrombosis, or hemorrhage and cardiac failure. Patients usually respond well to supportive therapy. Spontaneous resolution usually occurs in 2 weeks for nongravid patients and in 4-8 weeks in pregnant women. ${ }^{44}$

\section{To assist in decreasing the risk of multiple gestations:}

When 4 or more mature follicles are detected, the probability of having multiple gestations is high. ${ }^{27}$

\section{To identify congenital uterine anomaly and fallopian tube anomalies:}

Mullerian duct anomalies occur secondary to failure of organogenesis, failure of fusion or failure of reabsorption, causing incomplete development of one or both of the uterine horns. ${ }^{25}$ About $25 \%$ of women with mullerian duct anomalies have reproductive problems such as increased risk of spontaneous abortion, prematurity, intrauterine growth restriction (IUGR), abnormal fetal lie and dystocia at delivery. ${ }^{45}$ These anomalies are classified by the American Fertility Society (AFS) classification scheme. ${ }^{46}$ The scheme is based on the embryologic development of the mullerian ducts and is divided into 7 classes.

Class I: Uterine hypoplasia and/or agenesis

Class II: Unicornuate uterus

Class III: Uterus Didelphys

Class IV: Bicornuate uterus

Class V: Septate uterus

Class VI: Arcuate uterus and

Class VII: Diethylstilbesterol (DES) - related anomalies

For Class I: Uterine hypoplasia and/or agenesis, US demonstrates a fibrous remnant/connective tissue and vessels in the expected region of the uterus in the setting of agenesis and small hypoplastic uterine soft-tissue remnant in the setting of hypoplasia. The upper two- thirds of the vagina are absent or atretic in both conditions. Ovaries appear normal but may be more superiorly located. MRI will also show the same findings like ultrasonography but HSG evaluation is not indicated for this condition. Mayer-Rokitansky-Kuster-Hauser syndrome is the most common variant in this class of anomalies. $^{45}$

For Class II: Unicornuate uterus, US demonstrate a fusiform "banana-shaped" endometrial canal, which is laterally deviated with a single fallopian tube. If this is detected, it is better to do MRI to evaluate for a rudimentary horn which is often resected to avoid an increased risk of endometriosis and/or ectopic pregnancy. ${ }^{47}$ It is important to note that this condition is often associated with urinary tract anomalies with renal agenesis contralateral to the dominant uterine horn most commonly seen. ${ }^{25,45}$

For Class III: Didelphys uterus, US demonstrates 2 symmetric, widely spaced uterine horns each with its own cervix. Both HSG and MRI will show a similar picture. Failure to identify and canulate both cervices during HSG may lead to false diagnosis of unicornuate uterus. There is an association of urinary tract anomalies with this condition which is present in $23 \%$ of women with didelphys uterus. ${ }^{48}$

For Class IV: Bicornuate uterus, US demonstrates a fundal uterine cleft larger than $1 \mathrm{~cm}$ separating divergent uterine horns. It will also show fusiform symmetric size and appearance of the endometrial canals, with possible visualization of a communication between the inferior segments of the uterine horns. ${ }^{25}$

For Class V: Septate uterus, US demonstrates normal, flat or contour depression of the uterine fundus of less than $1 \mathrm{~cm}^{49}$ MRI will also show a similar presentation but HSG is limited in its ability to differentiate this from bicornuate uterus, a narrow angle of less than $75^{\circ}$ between the uterine horns and/or an intercornual distance of less than $4 \mathrm{~cm}$ is suggestive of septate uterus. ${ }^{49}$ TVS and MRI have improved the diagnostic accuracy for septate uterus with hysteroscopy and laparoscopy serving as gold standards for diagnosis. ${ }^{48}$ Of the mullerian duct anomalies, septate uterus is associated with the highest rate of reproductive failures. ${ }^{45}$ It is associated with infertility and miscarriages which is due to poor blood supply to the septum providing unsuitable support for the implanted embryo. ${ }^{50}$

For Class VI: Arcuate uterus, US demonstrates a single endometrial canal, with a smooth, broad indentation of the myometrium $(<1 \mathrm{~cm}$ at the uterine fundus). The external uterine contour is normal on both ultrasonography and MRI. HSG may be limited in distinguishing arcuate from septate uterus. ${ }^{25}$ An arcuate uterus may not have effect on fertility or obstetric outcomes. 51 
For Class VII: (T-shaped DES-related uterine anomalies). DES was previously used for treatment of hyperemesis gravidarum and prevention of spontaneous abortions between 1945 and 1970. Female fetus exposed to DES in utero are at risk of developing a hypoplastic, irregular Tshaped uterus and hypoplastic and strictured fallopian tubes, and they have an increased incidence of vaginal clear cell carcinoma later in life. ${ }^{52}$ In pregnant women who underwent in utero exposure to DES, the hypoplastic uterus incurs a higher risk of spontaneous abortion, preterm delivery and ectopic pregnancy. The features of DES-related uterine anomalies unlike other classes of mullerian duct anormalies, are best depicted by $\mathrm{HSG}^{53}$ US is limited in this demonstration. ${ }^{25}$

\section{To identify congenital ovarian anomalies}

Gonadal dysgenesis is a congenital anomaly in which gonadal tissue is replaced by fibrous stroma with no germ cells ${ }^{54}$. This condition is referred to as streak gonads. The most common form of this condition is secondary to Turner syndrome (45X0 karyotype). US is not performed to identify this condition. The diagnosis of this condition is based on clinical, biochemical, and karyotype identification. US demonstrates small oval to linear fibrous tissue within the broad ligament with absence of normal-appearing ovaries. This condition is best seen with MRI, although with limited detection, with gonads found in only $40 \%$ to $65 \%$ of cases. ${ }^{25}$ US has limited utility in detecting streak gonads, but may be useful for assessment of associated mullerian duct anomalies. ${ }^{25}$

\section{To identify acquired abnormalities}

(fibroids, endometrial polyps, adenomyosis, uterine synechiae and cervical stenosis). ${ }^{25,26}$

\section{Submucous fibroid}

Fibroids, also known as leiomyomas or myomas are benign estrogen-dependent smooth-muscle tumors that originate from the uterine myometrium, occurring in $20 \%$ to $40 \%$ of women in their reproductive years. ${ }^{1,55}$ They are solitary or multifocal lesions that arise from any part of the uterus. The masses that protrude into the endometrial canal, are described as submucous in location and cause infertility by interfering with embryo implantation. ${ }^{48,55,56}$ TVS demonstrates a focal heterogeneous mass that is hypoechoic to the myometrium and may have acoustic shadowing. ${ }^{57}$

\section{Endometrial Polyps}

Endometrial polyps are focal overgrowth of the endometrial glands and stroma surrounded by normal endometrium. These lesions are divided into 3 subtypes namely hyperplastic polyps which have glands similar to those seen in endometrial hyperplasia, atrophic polyps, which occur in postmenopausal women and have atrophic cystically dilated glands; and functional polyps which follow the menstrual cycle. ${ }^{55}$ TVS and/or sonohysterography are the imaging modalities of choice demonstrating a focal echogenic mass protruding into the endometrial lumen from the endometrium, with an intact endometrial stripe. MRI is used for indeterminate lesions with variable, appearance based on subtype.

\section{Adenomyosis}

Adenomyosis is a benign condition of the uterus which results from the invasion of myometrium by endometrial glands and stroma causing hyperplastic and hypertrophic changes of the myometrium. ${ }^{58}$ The process may be diffuse (with enlarged globular shape) or focal area which is referred to as an adenomyoma, which presents in 1 of 3 forms: as a localized version of the diffuse form; as a well-circumscribed nodule of smooth-muscle cells, endometrial glands and stroma or as a cyst secondary to repetitive bleeding, leading to cavitation. ${ }^{59,60}$ Adenomyosis is associated with infertility probably due to impaired uterine contractility required for directed sperm transport through the uterus. ${ }^{60}$

US is the initial imaging modality of choice demonstrating an enlarged globular uterus with loss of the junctional zone. Ultrasound features of adenomyosis include globular uterine enlargement, heterogeneous myometrial echotexture, myometrial cysts, indistinct endometrial-myometrial interface, subendometrial echogenic nodules or linear striations, asymmetric myometrial thickening and indistinct lesion borders. ${ }^{26}$

\section{Uterine Synechiae}

This is also known as intrauterine adhesions or intrauterine webs. They are adhesions of the endometrial canal leading to partial or complete loss of the uterine cavity and/or intrauterine cervical os. This condition may be as a result of trauma or destruction of the endometrial lining from previous pregnancy, infection, missed abortion and previous curettage. ${ }^{54,61}$ When this condition is associated with clinical symptoms of infertility, menstrual abnormalities, and/or recurrent pregnancy loss, the term Asherman syndrome is applied ${ }^{61}$. Ultrasound is limited in the detection of adhesions but may show irregular thickness of the endometrium with regions of hypoechogenicity consistent with areas of fibrosis.

HSG is the imaging technique of choice for the diagnosis of this condition, demonstrating irregular well-defined, angular and/or longitudinal filling defects within the endometrial canal. ${ }^{62}$ Sonohysterography is as effective as HSG in the detection of synechiae, with the added benefit of approximating the size of the endometrial cavity (Table 1).

\section{Cervical Stenosis}

It is the inability to insert a $2.5 \mathrm{~mm}$ or thinner dilator into the cervical canal. ${ }^{63}$ It could be congenital or secondary 
to infection. DES exposure in utero or iatrogenic trauma such as previous cone biopsy, cryotherapy, or laser vaporization of the cervix, causing scarring and fibrosis are risk factors. ${ }^{26,63}$ Cervical stenosis is best visualized on HSG. When there is complete obstruction, insertion of HSG catheter is blocked, prevailing imaging of the canal or interus. ${ }^{26,63}$ It may be necessary to have additional imaging with MRI or US to look for secondary signs of obstruction, including haematometra and hydrometra. ${ }^{63}$

\section{To identify acquired abnormalities of fallopian tube (Tubal occlusion, hydrosalpinx, salpingitis isthmica nodosa)}

Fallopian tube abnormalities are the most common cause of female infertility accounting for $30-40 \%$ of cases. ${ }^{64}$ Occlusion may occur at site along the course of the tube. The differential diagnosis of tubal occlusion includes tubal spasm, infection and prior surgery. ${ }^{62}$ Rare causes of tubal occlusion include granulomatous salpingitis due to tuberculosis, intraluminal endometriosis, parasitic infection and congenital atresia of the fallopian tubes. ${ }^{26}$

HSG is the gold-standard imaging modality in the diagnosis of occlusion within the fallopian tube (Table 1). The obstruction results in lack of intraperitoneal free spillage of contrast. ${ }^{65}$ When the obstruction is identified within the proximal cornual portion of the fallopian tube, differentiation from spasm must be considered with delayed imaging or administration of a spasmolytic agent such as scopolamine or glucagon to determine whether the obstruction is permanent or temporary. ${ }^{62,65,66,67}$ In addition it may be helpful to place the patient prone and re-inject contrast material into the uterus. ${ }^{56}$

\section{Hydrosalpinx}

It is the dilatation of the proximal tube as a result of blockage of ampullary portion of the fallopian tube taking on a classic sausage-shaped appearance. ${ }^{25}$ The condition is often bilateral and is caused by scarring or adhesions of the distal tube from PID, adhesions from previous pelvic surgery or trauma, endometriosis and tubal neoplasm. ${ }^{68,69}$ HSG demonstrates a dilated proximal tube with absence of free intra-peritoneal spillage of contrast. There is need for post procedural antibiotic prophylaxis (doxycycline) to prevent infection from stasis of contrast material within the obstructed tube. ${ }^{56}$ Ultrasound and MRI may show a fluid-filled tubular structure. The imaging characteristics of the fluid vary depending on whether the fluid is simple, hemorrhagic, protein or pus filled. ${ }^{68,69}$ (Table 1)

\section{Salpingitis Isthmica Nodosa}

It is an inflammatory process within the fallopian tube of unknown etiology, with small out-pouching on the isthmic portion of the fallopian tube. ${ }^{69}$ This condition is often associated with PID, infertility and occasionally ectopic pregnancy. $^{26,62}$ HSG demonstrates tubal irregularity and subcentimetric diverticula of the isthmus. This condition is often bilateral.

\section{Peritubal abnormalities}

Peritubal pooling of contrast materials is suggestive of peritubal adhesions. The abnormal accumulation of contrast material is usually seen adjacent to the ampullary ends of the tube at HSG. Both endometriosis and PID may lead to peritubal adhesions with resultant infertility. ${ }^{66}$ When there is evidence of peritubal adhesions at HSG, MRI is particularly helpful for further noninvasive evaluation. ${ }^{26}$ (Table 1 )

\section{To identify acquired abnormalities of the ovaries}

Ultrasound does not play a major role in the diagnosis of primary causes of ovarian factor infertility. The primary causes are nonfunctional ovaries, premature ovarian failure and gonadal dysgenesis. They are diagnosed based on clinical and biochemical findings. However, ultrasound can play a major role in detecting the secondary causes of ovarian factor infertility such as endometriosis and polycystic ovarian syndrome.

\section{Endometriosis}

It is the implantation of endometrial glands and stroma outside the endometrial cavity, primarily affecting the ovaries and peritoneal surfaces of the pelvis. ${ }^{70,71}$ Endometriosis often presents as chronic pelvic pain and infertility.

Ovarian lesions often present as cyst with hemorrhage (endometroma), deep invasion of endometriosis on the peritoneum resulting in fibrosis and muscular hyperplasia. Ultrasound of an endometroma demonstrates a thick-walled complex cyst with homogeneous low level echoes, often called chocolate cyst, and may have small calcification along the wall of the cyst. ${ }^{25,70}$ It is difficult to visualize peritoneal implants with ultrasound but can be suspected if there is tethering of the bowel or if the ovaries are in close approximation to the uterus. ${ }^{26,70} \mathrm{MRI}$ has unproved detection of peritoneal implants, but the sensitivity is low (13\%). ${ }^{25}$

\section{Polycystic ovary syndrome}

This is a syndrome in which 2 or 3 conditions must be present to make a diagnosis: (1) Oligo-ovulation and/or anovulation, (2) Hyperandrogenism without other cause, and (3) polycystic ovaries without other cause. Ultrasound plays an important role in this diagnosis by quantification of ovarian volume and assessment of cyst size and number. TVS is the imaging modality of choice, demonstrating ovarian volume greater than $10 \mathrm{ml}$, more than 12 cysts measuring 2 to $9 \mathrm{~mm}$ in diameter per ovary and increased echogenicity of the ovarian stroma. It is possible to have great overlap of these findings with normal ovarian ranges. ${ }^{26}$ 
Table 1: Imaging techniques. ${ }^{6,7,25-27}$

\begin{tabular}{|c|c|c|c|c|c|c|}
\hline $\begin{array}{l}\text { Type of } \\
\text { Imaging } \\
\text { Technique }\end{array}$ & $\begin{array}{l}\text { Routinely used } \\
\text { in evaluation of } \\
\text { infertile couple }\end{array}$ & $\begin{array}{l}\text { Information about } \\
\text { endometrial cavity } \\
\text { and fallopian tube }\end{array}$ & Draw back & Risks & $\begin{array}{l}\text { Average } \\
\text { cost }\end{array}$ & $\begin{array}{l}\text { Need for } \\
\text { Anesthesi } \\
\text { a }\end{array}$ \\
\hline $\begin{array}{l}\text { Transvaginal } \\
\text { Ultrasound } \\
\text { (TVS) }\end{array}$ & $\begin{array}{l}\text { Routinely used. } \\
\text { Uses sound } \\
\text { waves to obtain } \\
\text { medical images } \\
\text { of various } \\
\text { organs and } \\
\text { tissues in the } \\
\text { body. }\end{array}$ & $\begin{array}{l}\text { Limited accuracy in } \\
\text { diagnosing } \\
\text { abnormalities of the } \\
\text { endometrial cavity } \\
\text { and tubal pathology }\end{array}$ & $\begin{array}{l}\text { Well tolerated, } \\
\text { radiation free, } \\
\text { readily available, } \\
\text { cheap and easy to } \\
\text { use and can be } \\
\text { repeated }\end{array}$ & $\begin{array}{l}\text { Very low } \\
\text { risk of } \\
\text { heating }\end{array}$ & $\begin{array}{l}\$ 150-\$ \\
450 \\
\text { (less } \\
\text { expensive). }\end{array}$ & $\begin{array}{l}\text { No need } \\
\text { for } \\
\text { anesthesia }\end{array}$ \\
\hline $\begin{array}{l}\text { Hysterosalpi } \\
\text { ngography } \\
\text { (HSG) }\end{array}$ & $\begin{array}{l}\text { Not routinely } \\
\text { used. Less } \\
\text { preferred } \\
\text { procedure: } \\
\text { traditional } \\
\text { method used to } \\
\text { evaluate female } \\
\text { infertility. }\end{array}$ & $\begin{array}{l}\text { Gives extensive } \\
\text { information with } \\
\text { high sensitivity. } \\
\text { Gold standard in } \\
\text { the diagnosis of } \\
\text { tubal occlusion } \\
\text { within the fallopian } \\
\text { tube. }\end{array}$ & $\begin{array}{l}\text { Very low risk of } \\
\text { radiation exposure. } \\
\text { Inability to } \\
\text { distinguish a polyp } \\
\text { from a fibroid } \\
\text { tumor }\end{array}$ & $\begin{array}{l}1-3 \% \text { risk } \\
\text { of } \\
\text { infection, } \\
\text { abdominal } \\
\text { pain and } \\
\text { injury }\end{array}$ & $\begin{array}{l}\$ 600- \\
\$ 800\end{array}$ & Yes \\
\hline $\begin{array}{l}\text { Sono-HSG } \\
\text { (Fluid } \\
\text { Ultrasound) }\end{array}$ & $\begin{array}{l}\text { Not routinely } \\
\text { used. Provides } \\
\text { information on } \\
\text { pathological } \\
\text { lesions in } \\
\text { endometrial } \\
\text { cavity but } \\
\text { limited } \\
\text { information on } \\
\text { tubal patency. }\end{array}$ & $\begin{array}{l}\text { Lack of } \\
\text { comprehensive } \\
\text { evaluation of } \\
\text { fallopian tubes and } \\
\text { need for a second } \\
\text { procedure e.g. } \\
\text { hysteroscopy. }\end{array}$ & Easy tolerability. & $\begin{array}{l}\text { Low } \\
\text { infection } \\
\text { risk. }\end{array}$ & $\begin{array}{l}\$ 750- \\
\$ 1000\end{array}$ & $\begin{array}{l}\text { No Need } \\
\text { for } \\
\text { anesthesia }\end{array}$ \\
\hline MRI & $\begin{array}{l}\text { Not routinely } \\
\text { used. Uses } \\
\text { magnetic field, } \\
\text { radio waves and } \\
\text { computers to } \\
\text { generate images } \\
\text { of tissues within } \\
\text { the body. }\end{array}$ & $\begin{array}{l}\text { Detects } \\
\text { pathological lesions } \\
\text { including tubal } \\
\text { lesions and pituitary } \\
\text { adenoma. Best for } \\
\text { delineating } \\
\text { morphology, and } \\
\text { orientation of pelvic } \\
\text { structures. }\end{array}$ & $\begin{array}{l}\text { Noninvasive and } \\
\text { radiation free but it } \\
\text { has limited } \\
\text { availability and } \\
\text { high cost. Can't } \\
\text { easily be repeated. }\end{array}$ & $\begin{array}{l}\text { Contraindi } \\
\text { cated in } \\
\text { patients } \\
\text { with } \\
\text { cardiac } \\
\text { pacemaker } \\
\text { and } \\
\text { cochlear } \\
\text { implants. }\end{array}$ & $\begin{array}{l}\text { Expensive } \\
\text { (high cost) }\end{array}$ & $\begin{array}{l}\text { No need } \\
\text { for } \\
\text { anesthesia }\end{array}$ \\
\hline
\end{tabular}

\section{Limitations of ultrasonography}

Ultrasonographic limitations broadly include suboptimal visualization of fallopian tubes and broad ligament, failure to delineate small ovaries and inability to obtain images in the surgical plane, limited field of view, interference by obesity or by gaseous bowel loops and subjective errors. 5,6

US do not play major role in the diagnosis of primary causes of ovarian factor infertility such as nonfunctional ovaries, premature ovarian failure, and gonadal dysgenesis. However, US can play a major role in detecting the secondary causes of ovarian factor infertility such as endometriosis and polycystic ovarian syndrome. US also have limited utility in detecting streak gonads but may be useful for assessment of associated mullerian duct anomalies. The diagnosis of streak gonads is based on clinical, biochemical and karyotype identification.

US is limited in the demonstration of features of DESrelated anomalies such as hypoplastic, irregular T-shaped uterus and hypoplastic and strictured fallopian tubes unlike other classes of mullerian duct anomalies that are best depicted by HSG. ${ }^{25,53}$

US is limited in detection of uterine synechiae (intrauterine adhesions) but may show irregular thickness of the endometrium with regions of hypoechogenicity consistent with areas of fibrosis.

US is limited in detection of cervical stenosis but can be used to look for secondary signs of obstruction including haematometra and hydrometra. ${ }^{63}$ US is also limited in the 
detection of tubal occlusion. In this condition, HSG is the gold-standard imaging modality in the diagnosis of tubal occlusion within the fallopian tube.

\section{CONCLUSION}

Female Infertility is an immense stress to couples, families and relatives worldwide. The causes are multifactorial in origin with both congenital and acquired problems of the uterus, fallopian tubes and ovaries. Ultrasound plays an important role in female infertility work-up with HSG, sonohysterography and MRI, each playing a complimentary role in the screening, diagnosis, and/or management of female infertility.

Funding: No funding sources

Conflict of interest: None declared

Ethical approval: Not required

\section{REFERENCES}

1. Okeke TC, Ezenyeaku CCT, Ikeako LC. A review of treatment options available to women with uterine fibroids. British Journal of Medicine and Medical Research (BJMMR). 2015;6(12):1136-48.

2. Balogun SK. Age as correlate of incidence of vesicovaginal fistula (VVF): The Nigerian example. Issues Health Psychol. 1995;2:44-51.

3. Cousineau TM, Domar AD. Psychological impact of infertility. Best Pract Res Clin Obstet Gynaecol. 2007;21:293.

4. Haq IU, Mauzur S, Rehman AU, Farooq A. Role of ultrasonography in infertility management: Ovulation monitoring and assisted conception Annals. 2010;16(4):257-61.

5. Rastogi R. Role of imaging in female infertility (Dr. K.M Rai Memorial Oration Award). Indian J Radiol Imaging. 2010;20(3):168-73.

6. Padubidri VG, Daftary SN (eds). The pathology of conception. In: Howkins and Bourne Shaw's Textbook of Gynaecology. $13^{\text {th }}$ Edition. New Delhi, Elsevier. 2004;194-216.

7. Adekunle RA. Gynaecological Anatomy. In:Arulkumaran S, Synmonds IM, Fowlie A (eds), Oxford Handbook of Obstetrics and Gynaecology. $1^{\text {st }}$ edition. New Delhi, Oxford University Press. 2004;453-58.

8. Donald I, MacVicar J, Brown TG. "Investigation of abdominal masses by pulsed ultrasound". Lancet. 1958;1(7032):1188-195.

9. Woo Joseph. A short history of the development of ultrasound in obstetrics and Gynaecology obultrasound.net retrieved, 2007.

10. Weissman A, Mcardle CR, Achiron R. Ultrasound in Infertility. In:Seibel MM(ed), Infertility A Comprehensive Text. $2^{\text {nd }}$ edition. Connecticut, Appleton and Large. 1997;447-92.

11. Kratochwil A, Urban GU, Fredrick F. Ultrasonic tomography of the ovaries. Ann Chir Gynecol. 1972;61-211.
12. Hackeloer B, Nitschke S, Daume E, Sturm G, Buch holz R. Ultrasonics of ovarian changes under gonadotrophin stimulation. Geburtshilfe Frauenheilkd. 1977;38:185

13. Hacheloer BJ, Fleming R, Robinson HP, Adam AH, Coutts JRT. Correlation of ultrasonic and endocrinologic assessment of human follicular development. Am J Obstet Gynecol. 1979;135:12229.

14. Kerin JF, Warnes GM, Crocker J, et al. 3-hour urinary radio immunoassay for luteinizing hormone to detect onset of preovulatory LH surge. Lancet. 1980;1:430.

15. O'Herlithy C, de Crespigny L, Robinson HP. Monitoring ovarian follicular development with realtime ultrasound. BJOG 1980;87:613.

16. Montzavinos T, Garcia JE, Jones HW Jr. Ultrasound measurement of ovarian follicles stimulated by human gonadotropins for oocyte recovery and in intro fertilization. Fertile Steril. 1983;40:461.

17. Seibel MM, McArdle CR, Thompson IE, Berger MJ, Taymor ML. The role of ultrasound in ovulation induction: A critical appraisal. Fertil Steril. 1981;36:573.

18. Gleicher N, Friberg J. fullan N, et al. Egg retrieval for in vitro fertilization sonographically controlled vaginal culdocentesis. Lancet. 1983;2:508.

19. Dellenbach P, Nisand I, Moreau L, et al. Transvaginal sonographically controlled ovarian follicle puncture for egg retrieval. Lancet 1984;2:1467.

20. Schwimer SR, Lebovic J. Transvaginal pelvic ultrasonography. J Ultrasound Med. 1984;3:381.

21. Frederick J, Paulson RJ, Sauer MV. Routine use of vaginal ultrasonography in the preparative evaluation of gynecologic patients. An adjunct to resident education. J. Reprod Med. 1991;36:779.

22. Yee B, Barnes RB, Vargyas JM, Marrs RP. Correlation of Transabdominal and transvaginal ultrasound measurements of follicle size and member with laparoscopic findings for in vitro fertilization. Fertil Steril. 1987;47:828.

23. Andreotti RE, Thompson GH, Janowitz W, Shapiro AG, Zusmer NR. Endovaginal and transabdominal sonography of ovarian follicles. J Ultrasound. 1989;8:555.

24. Timor-Tritsch IE. Is office use of vaginal ultrasonography feasible? Am J Obstet Gynecol. 1990;162:983.

25. Kaproth-Joslin K, Dogra V. Imaging of Female Infertility. A Pictorial Guide to the Hysterosalpingography, Ultrasonography, and Magnetic Resonance Imaging findings of the Congenital and Acquired Causes of Female Infertility. Radio Clin N Am. 2013;51:967-81.

26. Steinkeler JA, Woodfield CA, Lazarus E, Hillstrom MM. Female Infertility: A Systematic Approach to Radiologic Imaging and Diagnosis. Radiographics. 2009;29(5):1353-70.

27. Nguyen KT. Female Infertility. In: Sauerberi EE, Nguyen KT, Nolan RL (eds). A Practical guide to 
Ultrasound in Obstetrics and Gynecology. $1^{\text {st }}$ edition. Philadelphia, Lippincott-Raven. 1998;104-9.

28. Ecochard R, Boehringer H, Rabilloud M, Marret H. Chronological aspects of ultrasonic, hormonal and other indirect indices of ovulation. BJOG. 2001;108:822.

29. Luttjeboer F, Harada T, Hughes E, et al. Tubal flushing for Subfertility. Cochrane Database Syst Rev. 2007:CD003778.

30. Goldberg BB, Liu JB, Kuhlman K, Merton DA, Kurtz AB. Endoluminal Gynecologic Ultrasound: Preliminary results. J Ultrasound Med. 1991;10:58390.

31. Bassil S. Changes in endometrial thickness, Width, Length and pattern in predicting pregnancy outcome during ovarian stimulation in vitro fertilization ultrasound Obstet Gynecol. 2001;18:258-63.

32. Fanchin R. Assessing uterine receptivity in 2001. Ultrasonographic glances at the New Millennium. An N Y Acad Sci. 2001;943:185-202.

33. Fleischer AC, Kepple DM, Vasquez J. Conventional and color Doppler transvaginal sonography in gynecologic infertility. Radiol Clin North Am. 1992;30:693-702.

34. Zhang X, Chen CH, Confino E, Barnes R, Milad M, Kazer RR. Increased endometrial thickness is associated with improved treatment outcome for selected patients undergoing in vitro fertilizationembryo transfer. Fertil Steril. 2005;2:336-40.

35. Ivanovski M, Lazarevski S, Popovik $M$, et al. Assessment of endometrial thickness and pattern in prediction of pregnancy in an in vitro fertilization an embryo transfer cycles after ovarian stimulation. Macedonian Medical Review. 2007;4-6:117-24.

36. Buckett WM. A Meta-analysis of ultrasound-guided versus clinical touch embryo transfer. Fertil Steril. 2003;80:1037-041.

37. Levi Setti PE, Albani E, Cavagna M, Bulletti C, Colombo GV, Negri L. The impact of embryo transfer on implantation - a review. Placenta. 2003;24(Suppl B):20-6

38. Woolcott R, Stanger J. Potentially important variables identified by transvaginal ultrasound-guided embryo transfer. Hum Reprod. 1997;12:963-6.

39. Sallam HN, Agameya AE, Rahman AF, Ezzeldin F, Sallam AN. Ultrasound measurement of the uterocervical angle before embryo transfer: a prospective controlled study. Hum Reprod. 2002;17:1767-72.

40. Goudas VT, Hammitt DG, Damario MA, Session DR, Singh AP, Dumesic DA. Blood on the embryo transfer catheter is associated with decreased rates of embryo implantation and clinical pregnancy with the use of in vitro fertilization-embryo transfer. Fertil Steril. 1998;70:878-82.

41. Lesny P, Killick SR. Tetlow RL, Manton DJ, Robinson J, Maguiness SD. Ultrasound evaluation of the uterine zonal anatomy during in vitro fertilization and embryo transfer. Hum Reprod. 1999;14:1593-8.
42. Pope CS, Cook EKD, Arny M, Novak A, Grow DR. Influence of embryo transfer depth on in vitro fertilization and embryo transfer outcomes. Fertil Steril. 2004;81:51-8.

43. Shamonki M, Schatman GL, Spandorfer SD, Rosenwaks Z. Ultrasound-guided embryo transfer may be beneficial in preparation for an IVF cycle. Hum Reprod. 2005;20(10):2844-9.

44. Dodson MG. Ovulation induction and transvaginal ultrasound. In:Transvaginal Ultrasound. New York: Churchill Livingstone. 1991;227-59.

45. Troiano RN, McCarthy SM. Mullerian duct anomalies: imaging and clinical issues. Radiology. 2004;233:19-34.

46. The American Fertility Society classification of adnexal adhesions, distal tubal occlusion, tubal occlusion secondary to tubal ligation, tubal pregnancies, mullerian anomalies and intrauterine adhesions. Fertil Steril. 1988;49:944-55.

47. Khati NJ, Fraizer AA, Brindle KA. The unicornuate uterus and its variants. $\mathrm{J}$ Ultrasound Med. 2012;31:319-31.

48. Taylor E, Gomel V. The uterus and fertility. Fertil Steril. 2008;89(1):1-16.

49. Pellerito JS, McCarthy SM, Doyle MB, Glickman MG, DeCherney AH. Diagnosis of Uterine anomalies: relative accuracy of MR Imaging, endovaginal sonography and hysterosalpingography, Radiology. 1992;183:795-800.

50. Homer HA, Li TC, Cokker ID. The Septate uterus: a review of management and reproductive outcome. Fertil Steril. 2000;73:1-14.

51. Tulandi T, Arronet GH, Mclnnes RA. Arcuate and bicornuate uterine anomalies and infertility. Fertile Steril. 1980;34:362-4.

52. Herbst AL, Senekjian EK, Frey KW. Abortion and Pregnancy loss among diethylstilbestrol-exposed women. Semin Endocrinol. 1989;7:124-9.

53. Riberio SC, Tormena RA, Peterson TV, et al. Mullerian duct anomalies: review of current management Sao Paulo Med J. 2009;127(2):92-6.

54. Choi HK, Cho KS, Lee KW, et al. MR Imaging of intersexuality. Radiographics. 1998;18:83-96.

55. Griffin Y, Sudigali V, Jacques A. Radiology of benign disorders of menstruation. Semin Ultrasound CT MR. 2010;116(3):747-58.

56. Thurmond AS. Imaging of female infertility. Radiol Clin North Am. 2003;41:757-67.

57. O’Neill M.J. Sonohysterography. Radiol Clin North Am. 2003:41:781-91.

58. Matalliotakis IM, Katsikis IK, Panidis DK. Adenomyosis: What is the impact on fertility? Curr Opin Obstet Gynecol. 2005;17:261-4.

59. Valentini AL, Gul SS, Sogali BG, et al. Adenomyosis from the sign of the diagnosis, imaging, diagnostic pitfall and differential diagnosis: a pictorial review. Radiol Med. 2011;116:1267-87.

60. Kunz G, Beil D, Huppert P, Noe M, Kissler S, Leyendecker G. Adenomyosis in endometriosis prevalence and impact on fertility. Evidence from 
magnetic resonance imaging. Hum Reprod. 2005;20:2309-316.

61. Deans R, Abborr J. Review of intrauterine adhesions. J Minim Invasive Gynecol. 2010;17(5):555-69.

62. Simpson WL, Beita LG, Mester J. Hysterosalpingography: a re-emerging study. Radiographics. 2006;26:419-31.

63. Valle RF, Sankpal R, Marlow JL, Cohen L. Cervical stenosis: a challenging clinical entity. J Gynecol Surg. 2002;18:129-43.

64. Sarto GE, Simpson JL. Abnormalities of the Mullerian and Wolffian duct systems. Birth Defects Orig Artic Ser. 1978;14:37-54.

65. Eng CW, Tang PH, Ong CL. Hysterosalpingography: Current applications. Singapore Med J. 2007;48(4):368-74.

66. Krysiewicz S. Infertility in women: diagnosis evaluation with hysterosalpingography and other imaging techniques. ARJ Am J Roentgenol. 1992;159:253-61.
67. Schankath AC, Fasching N, Urech-Ruh C, et al. Hysterosalpingography in the workup of female infertility: indications, technique, and diagnostic funding. Insights Imaging. 2012;3:475-83.

68. Kim MY, Rha SE, Oh SN. MR imaging findings of hydrosalpinx: a comprehensive review. Radiographics. 2009;29:495-507.

69. Chawla N, Kudesia S, Azad S, et al. Salpingitis isthmica nodosa. Indian $\mathrm{J}$ Pathol Microbiol. 2009;52:434-435.

70. Okeke TC, Ikeako LC, Ezenyeaku CCT. Endometriosis: a review article. Niger J Med. 2011;20(3):191-199.

71. Chamie LP, Blasbalg R, Pereira RM, et al. Findings of pelvic endometriosis at transvaginal US, MR imaging and laparoscopy. Radiographics. 2011;31:E77-100.

Cite this article as: Okeke TC, Agwuna KK, Ezenyeaku CC, Ikeako LC. Application of ultrasonography in female infertility: a comprehensive review. Int J Reprod Contracept Obstet Gynecol 2015;4:1246-56. 